\title{
INCEPTION OF HARMONISING DATA SILOS AND URBAN SIMULATION TOOLS USING 3D CITY MODELS FOR SUSTAINABLE MANAGEMENT OF THE URBAN FOOD WATER AND ENERGY RESOURCES
}

\author{
Rushikesh Padsala $^{1,3 *}$, Ernst Gebetsroither-Geringer ${ }^{2}$, Jan Peters-Anders ${ }^{2}$, Volker Coors ${ }^{1}$ \\ ${ }^{1}$ Stuttgart University of Applied Sciences, Schellingstr. 24, 70174 Stuttgart, Germany - (rushikesh.padsala, volker.coors)@ hft-stuttgart.de \\ ${ }^{2}$ AIT Austrian Institute of Technology GmbH, Giefinggasse 2, 1210 Vienna, Austria - (ernst.gebetsroither, jan.peters-anders)@ait.ac.at \\ ${ }^{3}$ Concordia University, 1515 St. Catherine St. West Montreal, QC, H3G 2W1 Canada - rushikesh.padsala@ mail.concordia.ca
}

KEY WORDS: Data Modelling, CityGML, Application Domain Extension, 3D City Models, Urban Food Water Energy Resources

\begin{abstract}
:
This paper explains the first insights into the ongoing development of a CityGML based Food Water Energy Application Domain Extension (FWE ADE). Cities are undergoing rapid expansion throughout the globe. As a result, they face a common challenge to provide food, water and energy (FWE) supplies under healthy and economically productive conditions. Consequently, new tools and techniques must be developed to support decision-makers, such as governments, public or private infrastructure providers, investors and city developers, to understand, quantify and visualise multiple interdependent impacts for the sustainable supply of the FWE resources. However, a common practice amongst these stakeholders is to work in their data silos, which frequently results in a lack of data integration and communication between domain specific simulation tools belonging to different infrastructure departments. As a result, insights related to critical indicators showing inter-dependency amongst different urban infrastructure are missed and hence, not included in the cities' redevelopment action plan. This paper documents the first ongoing attempt by an international group of domain experts from food, water, energy, urban design and geoinformatics to harmonise the data silos of food, water and energy domain for the case study regions of the County of Ludwigsburg in Germany, the city of Vienna in Austria and the neighbourhood of Gowanus in New York, the United States of America.
\end{abstract}

\section{INTRODUCTION}

Urbanisation, climate change and population growth are arguably three of the major challenges for the current and future redevelopment of cities worldwide. Not only it is estimated that by $205068 \%$ of the world population will shift to urban areas (UN, 2014) but also with the estimated population touching 9 billion, the water demand will have risen by $55 \%$, food demand by $60 \%$, and to facilitate the supply of food and water demand, the world economies would be using $80 \%$ more energy than today (OECD, 2014). Despite being the most significant contributors to the increase in greenhouse gas (GHG) emissions, coal, oil, and natural gas are widely used as the primary energy resources in various industries. Many countries and cities globally are establishing their carbon neutrality targets. The European Parliament recently approved their new climate law, setting an ambitious goal for European Union to reduce the overall carbon emission to $55 \%$ by 2030 and then aim to become the first climate-neutral continent by 2050 (EU, 2021). Advancing the transition to climate neutrality would not come without challenges. One such in particular would be finding a balance between the supply and demand of critical urban infrastructures such as food, water, and energy. One fundamental learning from the ongoing COVID-19 pandemic is that prevention and is always better than cure. The rising trend of population shifting to urban areas provides unprecedented challenges when considering the supply and demand of food, water and energy to the urban population and at the same time managing the amount of waste produced from these domains and making sure that the urban sprawl is restricted. This calls for analysing the entire urban system as a whole and not in their silos anymore. As a result, new tools, techniques and work-

\footnotetext{
* Corresponding author.
}

flows that can support decision-makers such as governments, public or private urban infrastructure providers, investors, city developers and citizens to understand, quantify, and visualise multiple interdependent impacts of the urban food, water and energy must be prioritised.

Together with many other domains, the use of Information and Communication Technology (ICT) has been long accepted as a supporting digital aid in the field of sustainable urban development. In particular, with the fast evolution of computer science and geospatial technologies, research centres along with public and private sectors have developed many open and proprietory Geographic Information system (GIS) and Remote Sensing software (e.g. ArcGIS, QGIS, ERDAS Imagine, GRASS GIS and others) which provided new digital methods for city planning and decision making. However, with such various geospatial tools and supporting data formats, a commonly adopted standardised urban data model to store and exchange information in an open information model related to different city objects (e.g. buildings, roads, vegetation, landuse, landcover and others) were crucial for data interoperability between tools and stakeholders. This need was further highlighted and implemented in 2008 by the Open Geospatial Consortium (OGC) by releasing and standardising an open City Information Model (3DCIM) called CityGML. Decision-makers in governments, public and private sectors related to city development, and other such stakeholders globally are just getting used to the vast potential of its use in developing a digital twin of their cities. With the continuous development of CityGML and under the open data initiatives from different governments, 3D city models of more than 100 mega-cities are freely available for public or private use (Delft University of Technology, 2019). Because CityGML is a standardised open data model and offers flexibil- 
ity to extend its core data models with domain-specific objects and attributes, it shows promising signs for developing a Food Water Energy Application Domain Extension (FWE ADE). If developed, such a cohesive data model has the potential to become a critical part of urban simulation softwares which can allow stakeholders to analyse and visualise the food, water and energy nexus, thus becoming a vital software infrastructure for the planning, operation and maintenance of smart, sustainable and resilient cities (Eicker et al., 2020).

This paper documents the first attempt in an ongoing development process of the FWE ADE. The later sections of the paper also show examples describing the role of FWE ADE in harmonising data silos and urban simulation tools for the case study regions of the County of Ludwigsburg in Germany, the city of Vienna in Austria and the neighbourhood of Gowanus in New York, the United States of America. The paper ends with further insights into the further development of the FWE ADE and its use in other case study region. The development of the FWE ADE is led by an international group of experts from the food, water, energy, urban design and geoinformatics domain. In the current state, the FWE ADE is targeted to CityGML v2.0.

\section{CITYGML AND ADE}

The OGC standardised CityGML is an XML-based open data model which describes ways of modelling digital 3D city models regarding its geometry, topology, semantics and appearance in five Level of Details (LoD). Different use cases have shown the usefulness of CityGML globally. For example, its use in neighbourhood planning (Agugiaro et al., 2020), disaster mapping (Schulte and Coors, 2009), energy demand simulation (Pad sala et al., 2020), noise mapping (Czerwinski et al., 2007), the Helsinki 3D+ Digital Twins applications (Airaksinen, 2019) and many other such urban modelling related use cases. CityGML, being an application-independent data model, does not contain application-specific classes and attributes. However, one of the many benefits of CityGML is its flexible object-oriented data model and a formalised mechanism to develop applicationspecific extensions called Application Domain Extension (ADE). With ADE, the core data model of CityGML can be extended with application-specific new classes and attributes. According to an extensive literature review on ADEs in 2018, around 44 ADE's were either already developed or in advanced development stages to support various applications, and domains (Biljecki et al., 2018). However, according to the literature review, no ADE exists to store multi-domain data objects and attributes such as food, water, energy, and support simulation workflows for FWE nexus. Out of all the available ADEs, particularly the Energy ADE (Agugiaro et al., 2018) and the Urban Planning ADE (Akahoshi et al., 2020) came close to the goals of FWE ADE and sustainable urban development. The Energy ADE supports urban scale energy modelling for building stocks. Its data model is used to store and calculate energy demand on a spatial scale of neighbourhoods, districts, or cities. Furthermore, it being an extension to CityGML allows open data exchange between different tools, users, and stakeholders. As of today, many urban energy simulators such as TEASER+ (Malhotra et al., 2019), EnergyPlus (Lilis et al., 2016), the Ladybug tools of Grasshopper plugin for Rhinoceros3D (Wang, 2020), CitySimPro (Rosser et al., 2019), and SimStadt (Nouvel et al., 2015), supports Energy ADE. Different use cases such as the County of Ludwigsburg in BadenWuerttemberg, Germany (Bruse et al., 2015), the district of Meidling in Vienna, Austria (Agugiaro, 2016), and the city of
Helsinki in Finland (Rossknecht and Airaksinen, 2020) have successfully demonstrated the use of Energy ADE in assessing building stock energy demands.

On the other hand, the Urban Planning ADE is a part of i-Urban Revitalisation (i-UR), an information infrastructure endorsed by the Japanese government. The two primary goals of i-UR are to showcase the urban development plan on 3D maps to citizens and encourage transparent and good faith efforts to meet the demands of concerned stakeholders. The usefulness of this ADE was evaluated through different data visualisation experiments carried in the Japanese municipalities of Munakata city, Chino city and Mutsu city. 3DCityDatabase (3DCityDB), an opensource tool built on top of PostgreSQL and Oracle to store, manage, exchange and visualise CityGML datasets, has extended its support to import and export both Energy ADE and Urban Planning ADE datasets by implementing custom Java based parsers. As examples to be used as templates for developing such custom parser to support import-export workflows in 3DCityDB for other ADEs, both the parser and its source code are made publicly available through the official 3DCityDB's GitHub page (3DCityDB, 2021).

Although with the Energy ADE, it is possible to model building stocks energy systems for its energy demand calculations, and with the Urban Planning ADE, it is possible to model necessary additional city object properties required for urban assessment and planning, a harmonised data model having necessary city object properties from urban planning integrated with the urban infrastructure of FWE systems is still missing. In this paper, a first attempt to develop a cohesive FWE ADE to support FWE based simulation workflows and its data visualisation is documented.

\section{THE FOOD WATER ENERGY ADE}

Figure 1 represents a conceptual model of a typical urban FWE infrastructure and its nexus.

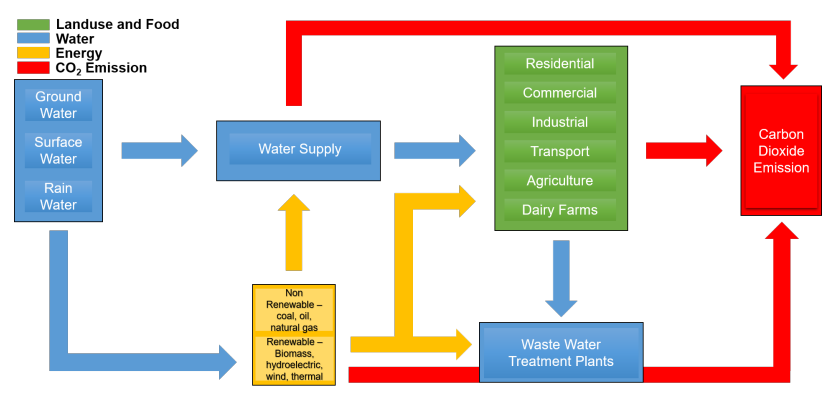

Figure 1. An urban FWE nexus conceptual model

A long term vision is to fully translate the FWE nexus conceptual model to an object-oriented CityGML FWE ADE. With this in mind, the primary objective of FWE ADE is to extend the existing CityGML data model to store FWE and its nexus related parameters so it can be used to exchange data between FWE based simulation workflows. For the use of FWE ADE at different spatial levels, it is further divided into four modules FWEBuilding, FWELanduse, FWEArea and FWESystem. Figure 2 shows the concept of FWE ADE at different spatial levels. Having FWE parameters connected to different spatial levels helps in scaling FWE simulation workflow results and introduces additional FWE parameters to a specific spatial level 

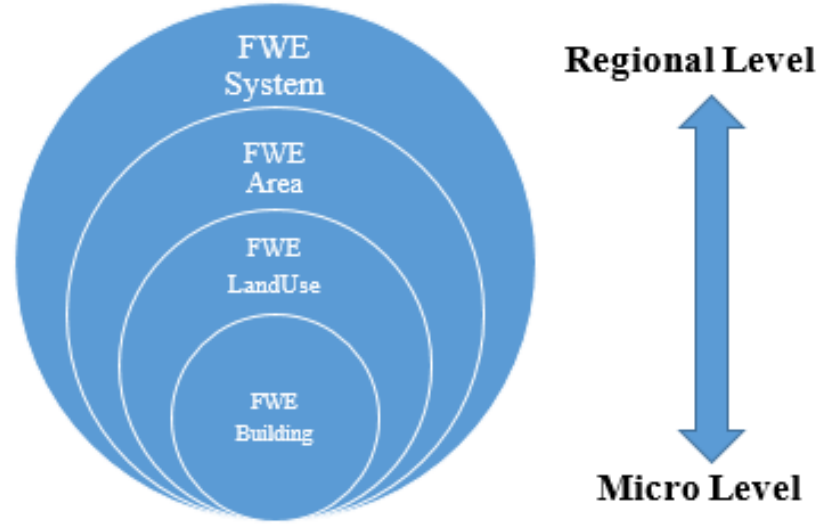

Figure 2. The FWE ADE conceptual diagram

for which data sets might not be available at a level higher or lower than the level targeted.

FWEBuilding and FWELandUse extends the CityGML data model for building and LandUse while, FWEArea and FWESystem are introduced as new city objects in the CityGML Core to store FWE related classes and attributes at the spatial level of political boundaries. Figure 3 shows the dependency of the FWE ADE modules on the CityGML modules.

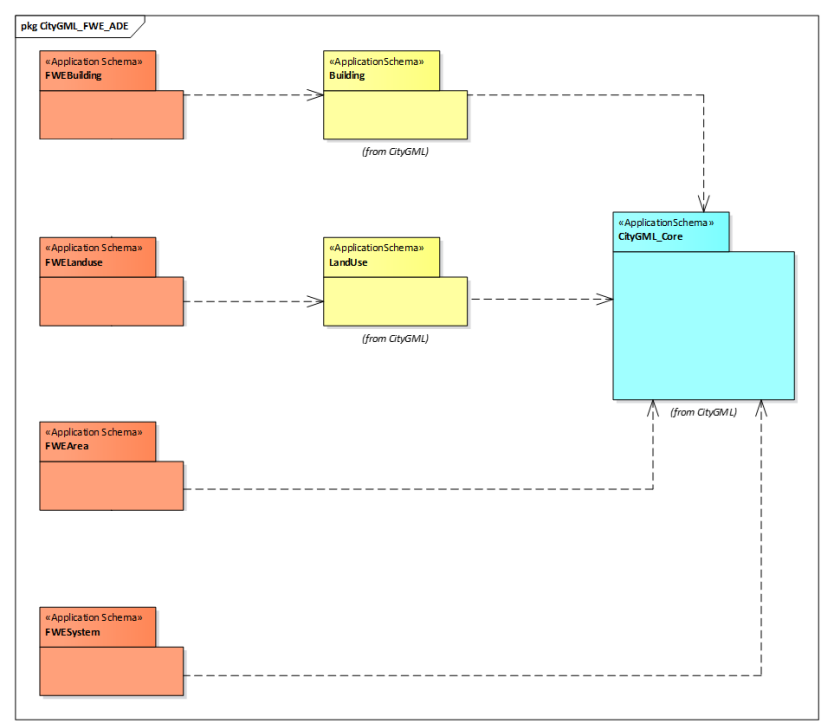

Figure 3. The UML package diagram for the FWE ADE

The following subsection explains the four FWE ADE modules in detail.

\subsection{FWEBuilding}

Figure 4 shows the class diagram for the FWEBuilding module. This module of FWE ADE extends the CityGML thematic module of building with its related FWE parameters. Those classes already defined in CityGML are imported unchanged. Here FWE parameters such as building usage and its energy demand, food and water demands of occupants, energy recovered from food and water waste, amount of rooftop photovoltaic potential are defined as attributes to the newly defined FWEBuilding classes. Class coloured in yellow is imported from CityGML.

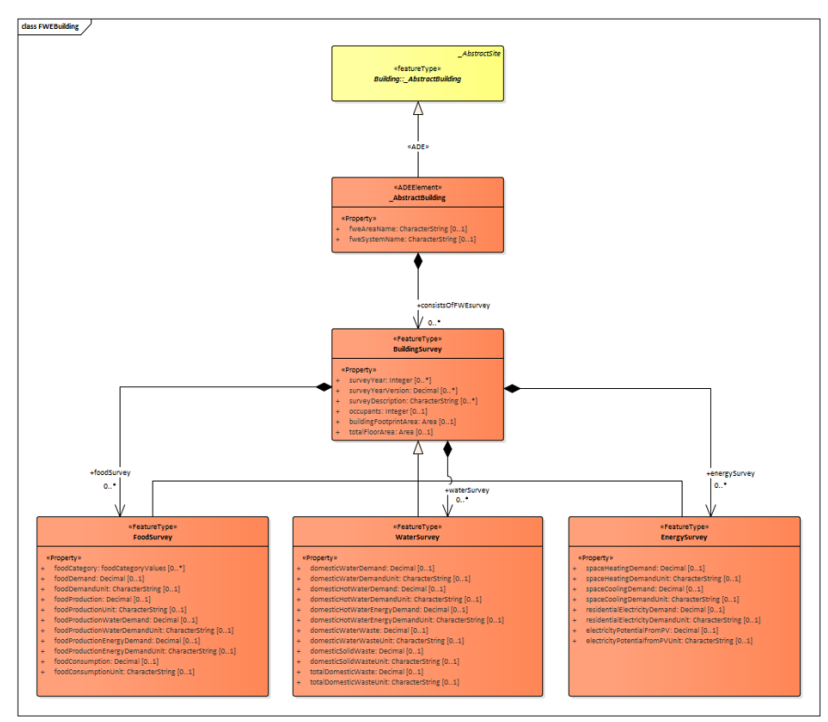

Figure 4. The UML class diagram for FWEBuilding

\subsection{FWELanduse}

Figure 5 shows the class diagram for the FWELanduse module. This module of the FWE ADE extends the CityGML thematic module of landuse with its related FWE parameters. Those classes already defined in CityGML are imported unchanged. Here FWE parameters such as landuse type and area, crop type for vegetation landuse, soil type, food production, electric and thermal energy from biomass, irrigation requirements, transpiration loss are defined as attributes to the newly defined FWELanduse classes. Class coloured in yellow is imported from CityGML.

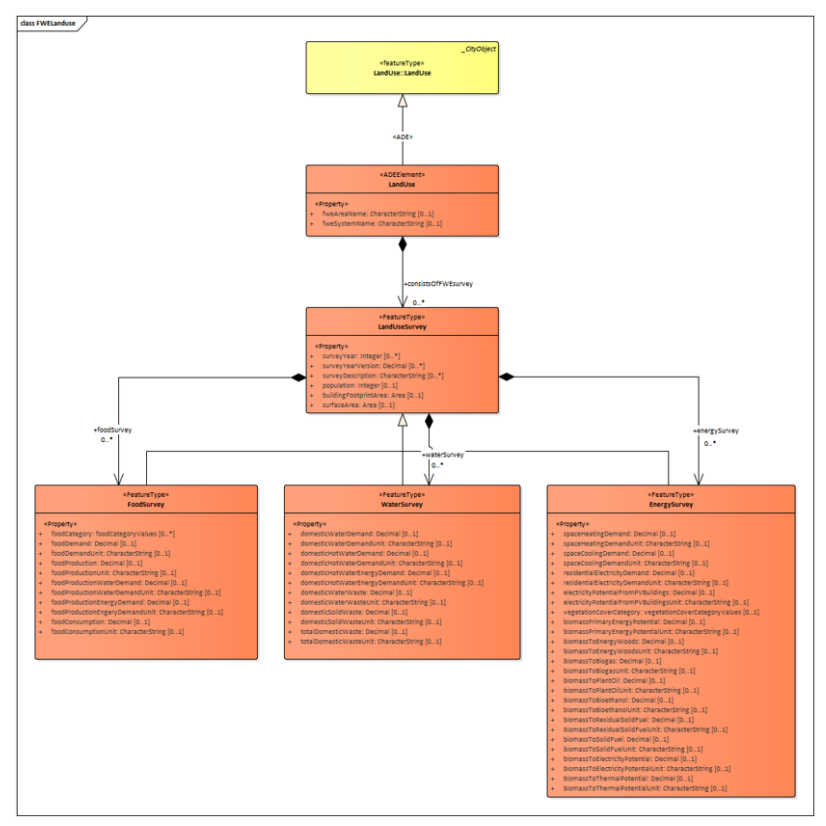

Figure 5. The UML class diagram for FWELanduse

\subsection{FWEArea}

Figure 6 shows the class diagram for the FWEArea module. This is defined as a new city object extended from the CityGML core having multisurface geometry. This geometry represents 
the political boundaries of study area. For example, the neighbourhood boundaries of New York or district boundaries of Vienna or town/municipality boundaries from the County of Ludwigsburg. Here FWE parameters such as the amount of food import, total area wise food, water and energy demand, total biomass potential available from agricultural lands, amount of energy that can be recovered from food and water wastes are defined as attributes. Class in blue represents the CityGML core class imported from CityGML, and class in dark yellow represents the geometry class.

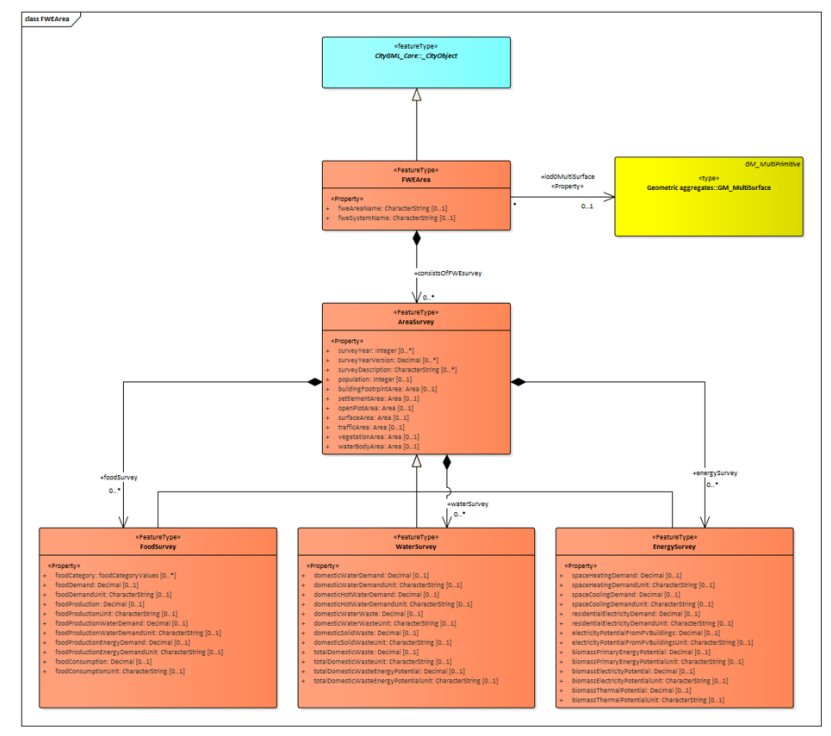

Figure 6. The UML class diagram for FWEArea

\subsection{FWESystem}

Like the FWEArea, FWESystem is also defined as a new city object extended from the CityGML core having multisurface geometry. However, instead of representing the political boundaries of the neighbourhood, district boundaries or municipality, the FWESystem represents the study area as a whole, for example, the County of Ludwigsburg's boundary. FWESystems' ADE classes and related FWE parameters remain the same as that of FWEArea.

All the UML diagrams and its XML schema definition files are made public on https://transfer.hft-stuttgart.de/gitlab/in-source/ fwe-ade.

\section{CASE STUDIES}

\subsection{County of Ludwigsburg, Germany}

The county of Ludwigsburg is a Southern German region situated in the middle of Baden-Württemberg state. It consists of 39 small to medium-sized towns and municipalities in Germany. The State Office for Geoinformation and Rural Development (LGL) Baden-Württemberg provided CityGML building models for all the 39 towns and municipalities of Ludwigsburg county. Additionally, the landuse dataset in shapefile data format was provided by the Federal Agency for Cartography and Geodesy (BKG). To test the FWE ADE and develop new FWE based simulation workflows, SimStadt was used. SimStadt is an urban energy simulation platform developed to help public authorities plan and manage energy transition on an urban scale. SimStadt uses CityGML datasets to run various urban energy simulation workflows. First, the existing workflow to calculate the energy demand of building stocks was used. The necessary CityGML building attributes of building functions and year of construction were first enriched by merging it with geodata acquired from a local private data provider Nexiga. The output of SimStadt's energy demand workflow produced values of specific heating demand and domestic hot water demand for each CityGML building. These results were then stored in the FWEBuilding module of the FWE ADE using Feature Manipulation Engine (FME). FME is a well-accepted spatial Extract, Transform and Load (ETL) software supporting data integration, management and transformation of more than 450 data formats. Figure 7 shows the web 3D visualisation of Marbach's building stock heat demand. The web $3 \mathrm{D}$ visualisation was built using the OGC standard of 3D tiles and the open source JavaScript library CesiumJS.

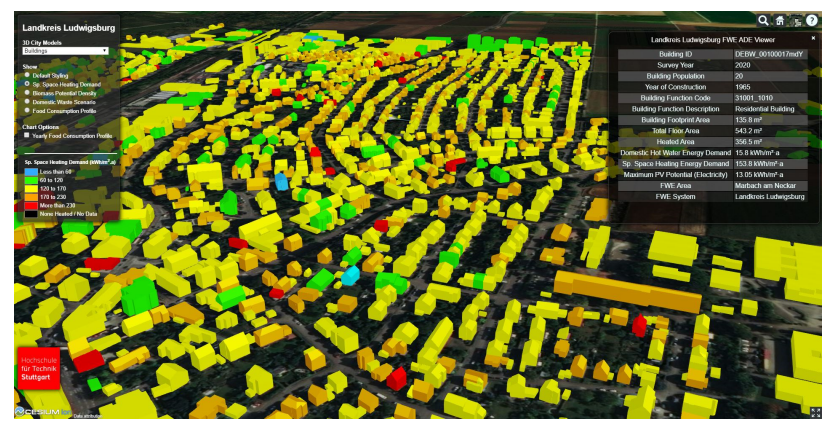

Figure 7. Marbach's building stock heat energy demand visualisation

Thereafter, a new FWE based bioenergy simulation workflow was developed in SimStadt to 1) estimate the bioenergy potential from biomass and 2) evaluate the regional bioenergy potentials and its impact on water demand. A high level workflow of the newly developed bio-energy workflow is shown in figure 8 .

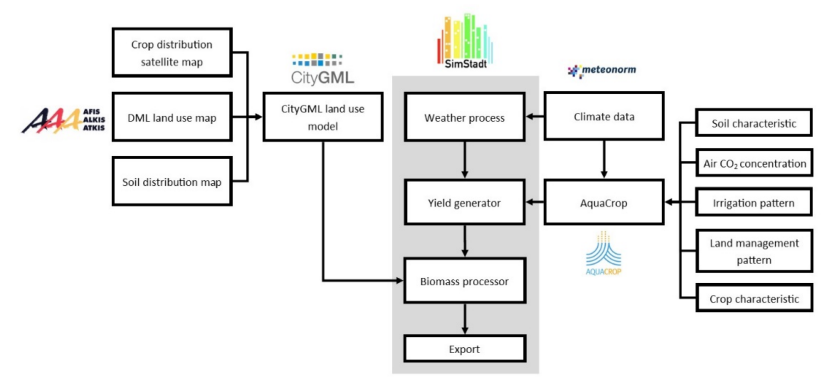

Figure 8. Newly developed SimStadt's bio-energy workflow (Bao et al., 2020a)

As primary input to the SimStadt's bioenergy workflow, first, the landuse data provided by the BKG was further enriched with crop type dataset openly available from the EU Copernicus programme (Griffiths et al., 2018) and soil type dataset openly available from the Federal Institute for Geosciences and Natural Resources (BGR). Figure 9 shows Marbach's landuse map enriched with crop and soil type. Because the SimStadt's bioenergy workflow takes CityGML landuse dataset as its input, the enriched landuse map was converted to CityGML and stored in the FWELanduse module of the FWE ADE as shown in figure 10 

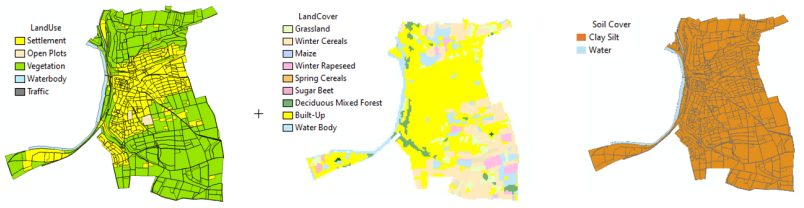

(a)Landuse

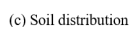

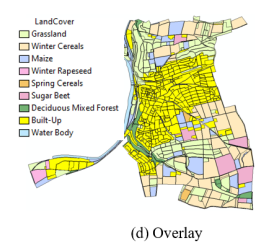

Figure 9. Marbach's landuse map enriched with soil and crop type (Bao et al., 2020a)

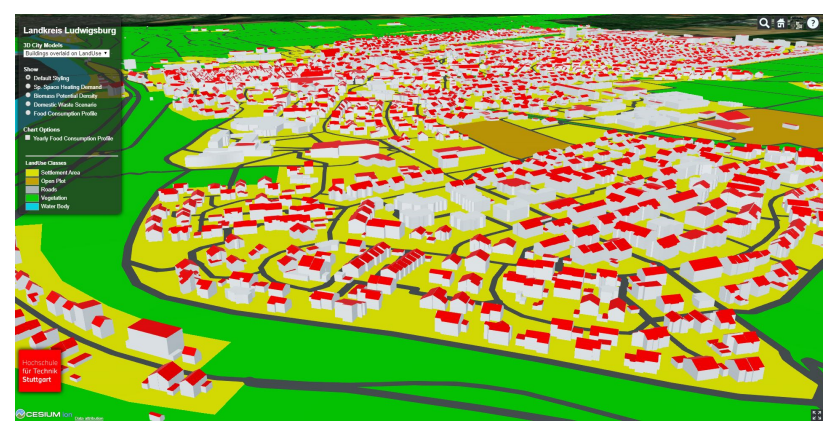

Figure 10. Marbach's landuse data visualised with its building stock on web

Figure 11 shows the use of SimStadt's bioenergy workflow with the FWELanduse.

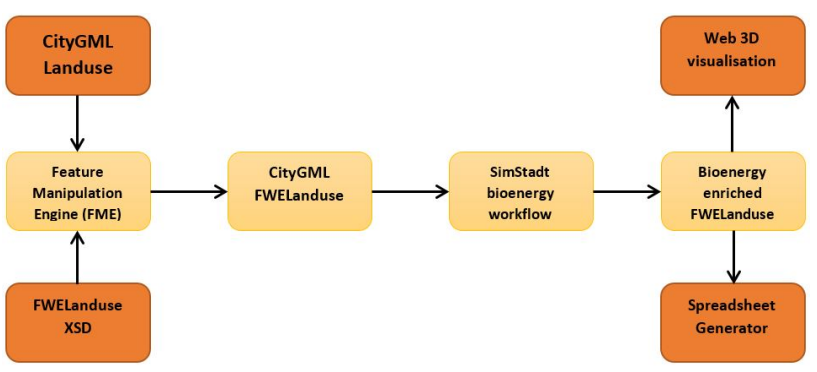

Figure 11. The the use of FWELanduse with SimStadt's bioenergy workflow

Figure 12 shows Marbach's biomass potential on web.

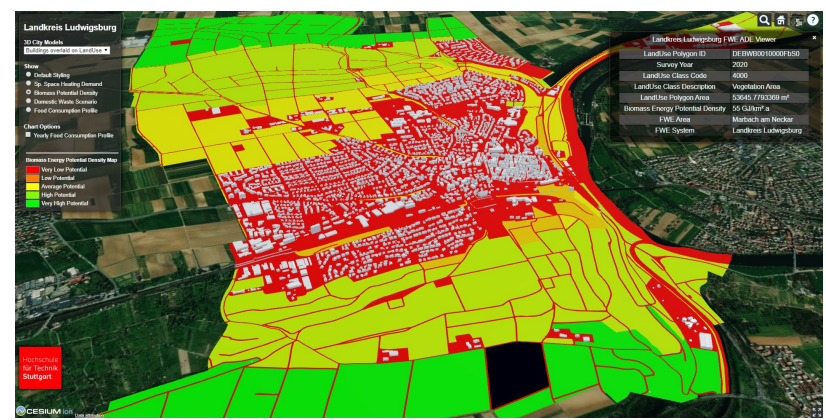

Figure 12. Marbach's biomass potential visualisation

Additionally, literature derived temporal food consumption dataset (Dobisch, 2019) for the county of Ludwigsburg was stored in FWESystem module and visualised as show in figure 13

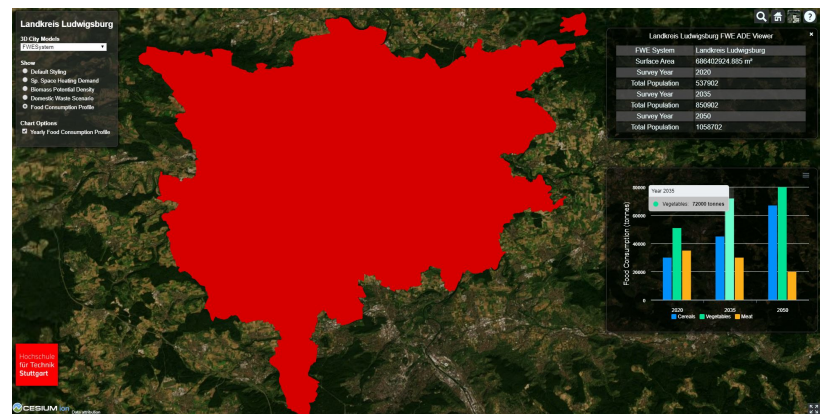

Figure 13. Temporal food consumption profile for County of Ludwigsburg

In a separate study, the FWEBuilding module is again used to store census derived building occupancy details to estimate water demand for residential and non-residential buildings (Bao et al., 2020b).

\subsection{City of Vienna, Austria}

The city of Vienna is medium dense and one of the fastest growing European city. Through their open data initiatives, the CityGML building stock models covering the entire Vienna is freely available. Its development process taking Meidling district as its case study is well described as one of the many outputs from the European Marie-Curie Ci-ENERGY project (Agugiaro, 2016). Within the project, the CityGML building stock dataset for Meidling was enriched with attributes such as building function, year of construction, building address, occupants and then used for its heat energy demand calculation (Skarbal et al., 2017). However, on geometrical validation using CityDoctor, it was found that the bounding surface geometries of roof, wall and ground were duplicated to generate its building solid geometry. This contradicts the CityGML conformance requirement 10.3.9.4 which instructs using xlink mechanism of GML to generate building solids. The effect of geometrical errors in CityGML building model on its energy demand calculations is well explained by (Coors et al., 2020). As a result, after correctly re-injecting building solids (Padsala and Coors, 2019) heat energy demand was recalculated using SimStadt. In addition, rooftop photovoltaic potential calculations were also made using SimStadt. These results were stored in the FWEBuilding module and then used for web visualisation as shown in figure 14 and figure 15

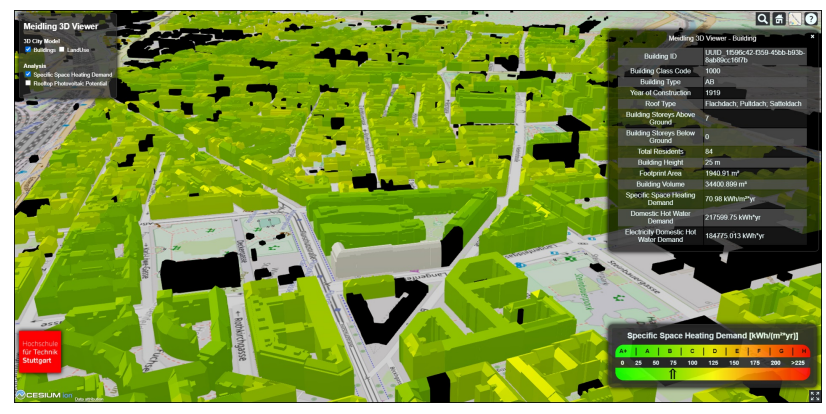

Figure 14. Meidling's building stock heat energy demand visualisation 


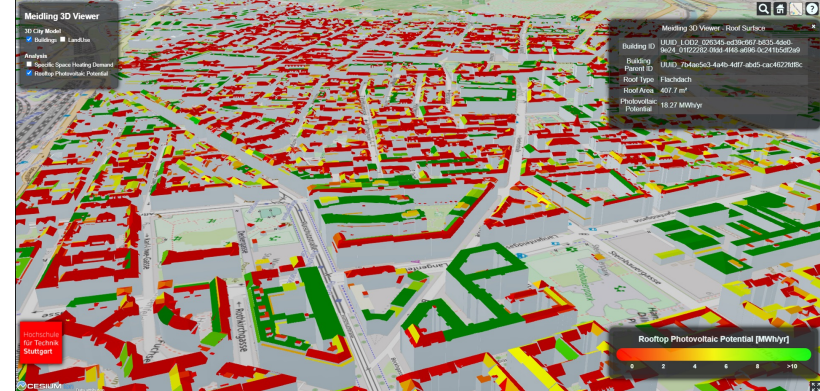

Figure 15. Meidling's roof top PV potential visualisation

Furthermore, an example usecase of FWE ADE to connect domain specific urban simulation tools URBANICA and Simstadt is under development. Urban Infrastructure Development Simulator (URBANICA) is an urban growth and landuse change simulation software (Gebetsroither-Geringer et al., 2016). Landuse dataset of Vienna (Realnutzung) published as open data by the city of Vienna will be used as a primary input. Here the hypothesis of 1)whether with the existing landuse dataset, can the current bioenergy potential of Vienna be estimated using SimStadt and 2)can a simulated future landuse dataset generated from URBANICA be used to calculate future bioenergy potential of Vienna using SimStadt is under investigation.

As shown in figure 16 the data exchange between URBANICA and SimStadt is proposed to happen through the FWELanduse module of the FWE ADE and 3DCityDB. Extending the importer-exporter workflow of 3DCityDB to support the FWE $\mathrm{ADE}$ is currently under development.

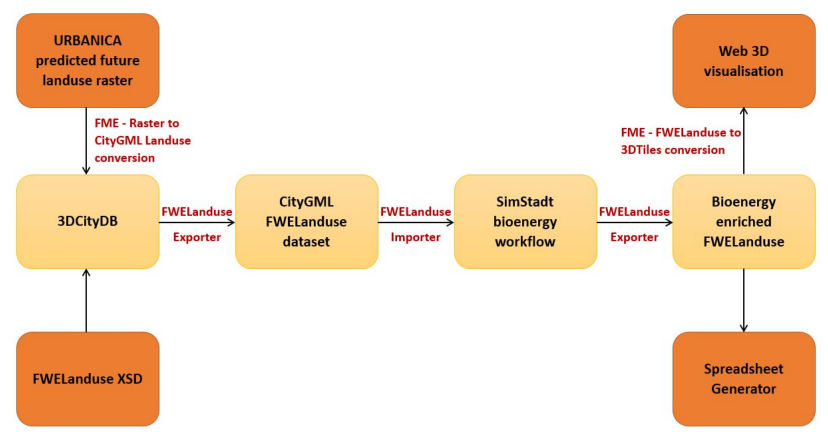

Figure 16. A proposed data exchange workflow between Urbanica and SimStadt

Figure 17 shows the existing landuse dataset of Vienna converted to CityGML and stored in the FWELanduse.

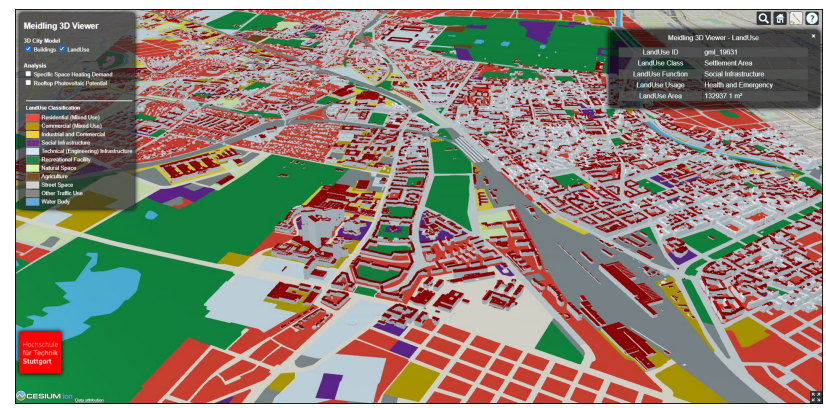

Figure 17. Meidling's landuse data visualised with its building stock on web
Harmonising landuse dataset with crop type dataset required as an additional parameter to run the bioenergy potential workflow in SimStadt is also under process. Additionally, a connection between the landuse dataset, bioenergy potential and Human Appropriation of Net Primary Production (HANPP) is being studied. HANPP is a regional ecological model which helps in quantifying the effects of human-induced changes in land productivity and harvest on ecological biomass flows (Krausmann et al., 2013).

\subsection{Neighbourhood of Gowanus, New York, USA}

The case study region of Gowanus (previously known as South Brooklyn) is a neighbourhood in the New York City (NYC) borough of Brooklyn. Originally a dominant industrial zone, it is now under redevelopment led by NYC's planning department in collaboration with the American Institute of Architects New York Chapter (AIANY), New York Institute of Technology (NYIT) and community stakeholders. A CityGML model for the existing building stock of Gowanus is available free of cost from New York's open data portal. Its development process is well described in an article published by TU Munich (Kolbe et al., 2015). Based on population projections for the year 2050 and following NYC landuse mapping guidelines, a business as usual and best practise 2050 scenario, 3D building geometries were modelled using Rhinoceros 3D. These three scenarios of existing, business as usual and the best practice 2050 scenario were later simulated for its energy demand using SimStadt. The values of heating energy demand and domestic hot water demand were stored in the FWEBuilding module and later used for web visualisation as shown in figure18. A data conversion process from Rhinoceros $3 \mathrm{D}$ to the semantic data model of CityGML and its use with SimStadt is explained in the article by (Padsala et al., 2020).

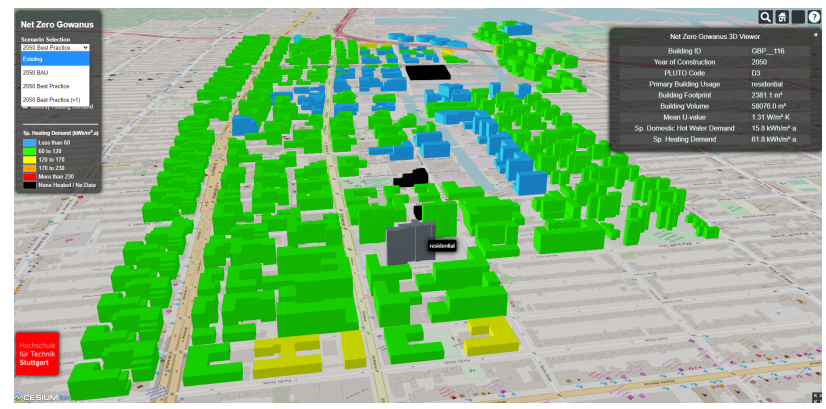

Figure 18. Gowanus' best practise 2050 scenario visualised with its heating demand

The intentions behind running energy simulation for the modelled building stock scenarios of business as usual and best practice is to incorporate the energy demand calculation in the urban design process from the beginning. Traditionally, urban designers' focus was on designing and characterising the physical arrangement of the urban elements. However with the climate change adaptation and mitigation policies such as the 80 $\mathrm{x} 50$ policy of $\mathrm{NYC}$ aiming to cut down carbon emissions by $80 \%$ until 2050 (NYC, 2014) and continuous development of new tools and techniques which allow data exchange between domain-specific tools have helped urban designers and architects design more climate-friendly building stocks. Additionally, the possibilities of harmonising data from wastewater treatment plants in the FWE ADE to develop new simulation workflows to estimate energy recovery from wastewater is under development. 


\section{CONCLUSION AND OUTLOOK}

This paper presented a first attempt to develop a cohesive food water energy ADE (FWE ADE). Its module of FWEBuilding, Landuse, Area and System allowed users to harmonise datasets available on different spatial levels. Furthermore, new FWE related workflows were developed to simulate datasets harmonised from different data silos having different data formats. For example, in the use case of the county of Ludwigsburg. Additionally, the case study of the city of Vienna and the neighbourhood of Gowanus showed how a data exchange mechanism could be developed to harmonise different urban modelling and simulation toolsets to estimate and visualise future urban FWE demands and potentials. Such use cases show the effectiveness of having a cohesive data model such as FWE ADE is critical and can potentially form a backbone for more such integrated FWE nexus simulations. The FWE ADE is far from complete and over time and different use cases further studies are being carried around in extending the current state of the ADE with new FWE objects, parameters and their relationships. For instance, to support a new urban green workflow, FWE related parameters for the CityGML building roof and wall surfaces are being collected to study the impact of green roofs on the roofs PV potential, buildings heating demand and stormwater run-off. In another study on the Ville-Marie area of Montreal, Canada, new building level FWE parameters are being identified to estimate the energy recovery potential from food waste and water waste. Its first results are shown in figure 19

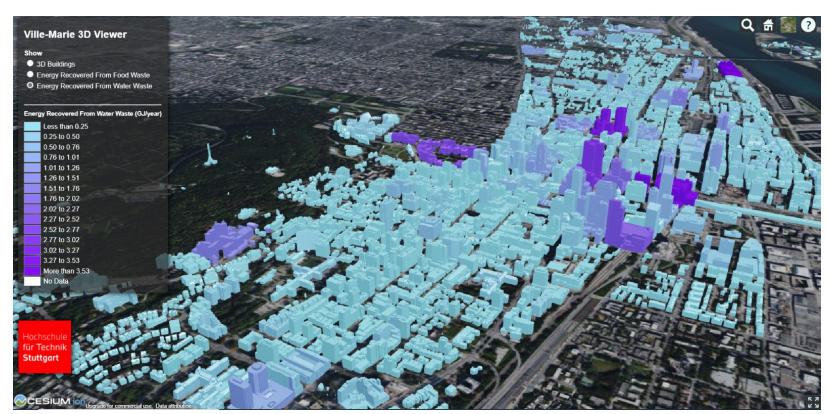

Figure 19. Energy recovered from water waste in the Ville-Marie area of Montreal, Canada (Braun et al., 2021)

In terms of data management, further investigation on more flexible ways of data harmonisation between data silos are required. As per an estimation, the worldwide data will grow by $61 \%$, reaching 175 zettabytes by 2025 (IDC, 2018). Harmonising data silos and storing it on a local database will increase the data volume further, leading to data duplication and data pollution if not managed properly. Rather, using Application Programming Interface (APIs) to harmonise data silos shows promising signs (Santhanavich and Coors, 2020) (Salesforce, 2020). With the continuous development of FWE ADE and its related workflows, more intuitive visualisation tools using 3D city models can help stakeholders and decision makers make a comprehensive analysis and monitor interdependencies between different urban infrastructure. Causal loop diagrams are one way to visualise how different variables in urban infrastructure are interrelated. However, it misses the visual quality and experience which 3D city models can provide. With such cohesive data modelling and visualisation toolsets, it is also equally important to motivate the domain-specific stakeholders and decision-makers to analyse a city as one ecosystem and not in their domain silos.

\section{ACKNOWLEDGEMENTS}

This paper is part of the IN-SOURCE (INtegrated analysis and modeling for the management of sustainable urban FEW ResSOURCEs) project, which is funded from the European Union's Horizon 2020 research and innovation program under grant agreement No 730254. We would like to give our acknowledgements to the JPI Urban Europe, the Belmont Forum, the Federal Ministry of Education and Research - BMBF Germany and the Federal Ministry Republic of Austria Climate Action, Environment, Energy, Mobility, Innovation and Technology (BMK) for their financial support to the project IN-SOURCE. For the geodatasets used in the paper we would like to thank The State Office for Geoinformation and Rural Development (LGL) BadenWürttemberg, The Federal Agency for Cartography and Geodesy (BKG), Germany and Vienna's Municipal Department 41 - Urban Survey (MA41). We would also like to thank our international IN-SOURCE project partners from the USA, New York Institute of Technology (NYIT), the City University of New York (CUNY) and Prof. Dr. Ursula Eicker from Concordia University, Montreal, Canada for their continued help and support.

\section{REFERENCES}

3DCityDB, 2021. energy-ade-citydb. github.com/3dcitydb.

Agugiaro, G., 2016. First Steps Towards An Integrated Citygml-Based 3d Model Of Vienna. ISPRS Annals of Photogrammetry, Remote Sensing and Spatial Information Sciences.

Agugiaro, G., Benner, J., Cipriano, P., Nouvel, R., 2018. The Energy Application Domain Extension for CityGML: enhancing interoperability for urban energy simulations. Open Geospatial Data, Software and Standards.

Agugiaro, G., González, F., Cavallo, R., 2020. The City of Tomorrow from... the Data of Today. ISPRS International Journal of Geo-Information.

Airaksinen, E., 2019. The kalasatama digital twins project.

Akahoshi, K., Ishimaru, N., Kurokawa, C., Tanaka, Y., Oishi, T., Kutzner, T., Kolbe, T., 2020. I-Urban Revitalization: Conceptual Modeling, Implementation, And Visualization Towards Sustainable Urban Planning Using CityGML. ISPRS Annals of the Photogrammetry, Remote Sensing and Spatial Information Sciences.

Bao, K., Padsala, R., Coors, V., Thrän, D., Schröter, B., 2020a. A Method for Assessing Regional Bioenergy Potentials Based on GIS Data and a Dynamic Yield Simulation Model. energies.

Bao, K., Padsala, R., Thrän, D., Schröter, B., 2020b. Urban Water Demand Simulation in Residential and Non-Residential Buildings Based on a CityGML Data Model. ISPRS International Journal of Geo-Information.

Biljecki, F., Kumar, K., Nagel, C., 2018. CityGML Application Domain Extension (ADE): overview of developments. Open Geospatial Data, Software and Standards volume.

Braun, R., Padsala, R., Malmir, T., Mohammadi, S., Eicker, U., 2021. Using 3D CityGML for the Modeling of the Food Waste and Wastewater generation -A Case Study for the City of Montréal. Frontiers in Big Data, section Data-driven Climate Sciences. 
Bruse, M., Nouvel, R., Wate, P., Kraut, V.and Coors, V., 2015. An Energy-Related CityGML ADE and Its Application for Heating Demand Calculation. International Journal of 3-D Information Modeling (IJ3DIM).

Coors, V., Betz, M., Duminil, E., 2020. A Concept of Quality Management of 3D City Models Supporting Application Specific Requirements. Journal of Photogrammetry, Remote Sensing and Geoinformation Science.

Czerwinski, A., Sandmann, S., Stocker-Meier, E., Plumer, L., 2007. Sustainable SDI for EU noise mapping in NRW - bestpractice for INSPIRE. International Journal of Spatial Data Infrastructures Research.

Delft University of Technology, 2019. Cities/regions around the world with open datasets. 3d.bk.tudelft.nl/opendata/opencities/.

Dobisch, L., 2019. Food metabolism in ludwigsburg, msc thesis, university of applied sciences esslingen.

Eicker, U., Weiler, V., Schumacher, J., Braun, R., 2020. On the design of an urban data and modeling platform and its application to urban district analyses. Energy and Buildings.

EU, 2021. EU climate action and the European Green Deal. ec.europa.eu/clima/policies/eu-climate-action.

Gebetsroither-Geringer, E., Loibl, W., Köstl, M., PetersAnders, J., 2016. Smart urban simulation tools for planning decision support need smart data and smart data gathering methods. Real CORP 2016.

Griffiths, P., Nendel, C., Hostert, P., 2018. National-scale cropand land-cover map of germany (2016) based on imagery acquired by sentinel-2a msi and landsat- 8 oli. pangaea.

IDC, 2018. Expect 175 zettabytes of data worldwide by 2025 .

Kolbe, T., Burger, B., Cantzler, B., 2015. Citygml goes to broadway. Photogrammetric Week' 15.

Krausmann, F., Erb, K., Gingrich, S., Haberl, H., Bondeau, A., Gaube, V., Lauk, C., Plutzar, C., Searchinger, T., 2013. Global human appropriation of net primary production doubled in the 20th century. Proceedings of the National Academy of Sciences of the United States of America.

Lilis, G., Giannakis, G., Katsigarakis, K., Costa, G., Sicilia, A., García-Fuentes, M., Rovas, D., 2016. Simulation model generation combining ifc and citygml data. European Conference on Product and Process Modelling (ECPPM).

Malhotra, A., Jérôme-Frisch, M., Treeck, C., 2019. Parametric study of different levels of detail of citygml and energy-ade information for energy performance simulations. Proceedings of Building Simulation 2019: 16th Conference of IBPSA.

Nouvel, R., Brassel, K., Bruse, M., Duminil, E., Coors, V., Eicker, U., Robinson, D., 2015. Simstadt, a new workflowdriven urban energy simulation platform for citygml city model. CISBAT 2015, Future Buildings Districts - Sustainability from Nano to Urban Scale.

NYC, 2014. New York City’s Road Map to 80 x 50.

OECD, 2014. Water, Energy, Food Nexus. www.oecd.org/development/water-energy-food-nexus.htm.
Padsala, R., Coors, V., 2019. Solidinjector. gitlab.com/volkercoors/CiD4Sim/-/wikis/usefulTools/FMEWorkbenches.

Padsala, R., Fink, T., Peters-Anders, J., Gebetsroither-Geringer, E., Coors, V., 2020. From urban design to energy simulation - a data conversion process bridging the gap between two domains. Real CORP 2020.

Rosser, J., Long, G., Zakhary, S., Boyd, D., Mao, Y., Robinson, D., 2019. Modelling Urban Housing Stocks for Building Energy Simulation Using CityGML EnergyADE. ISPRS International Journal of Geo-Information.

Rossknecht, M., Airaksinen, E., 2020. Concept and Evaluation of Heating Demand Prediction Based on 3D City Models and the CityGML Energy ADE - Case Study Helsinki. ISPRS International Journal of Geo-Information.

Salesforce, 2020. What are data silos?

Santhanavich, T., Coors, V., 2020. CityThings: An integration of the dynamic sensor data to the 3D city model. Environment and Planning B: Urban Analytics and City Science.

Schulte, C., Coors, V., 2009. Development of a citygml adefor dynamic 3d flood information. Proceedings of Applied Geoinformatics for Society and Environment (AGSE).

Skarbal, B., Peters-Anders, J., Faizan Malik, A., Agugiaro, G., 2017. How to Pinpoint Energy-Inefficient Buildings? An Approach Based on the 3D City Model of Vieena. ISPRS Annals of the Photogrammetry, Remote Sensing and Spatial Information Sciences.

UN, 2014. World Urbanization Prospects: The 2014 Revision.

Wang, X., 2020. Using citygml energyade data in honeybee: Msc thesis in geomatics for the built environment, delft university of technology. https://repository.tudelft.nl/islandora/object/uuid:fb35db7c9af8-488c-8d0b-263b138d8fd3. 